\title{
Qualitative stability assessment of cut slopes along the National Highway-05 around Jhakri area, Himachal Pradesh, India
}

\author{
Jagadish Kundu ${ }^{1}$, Kripamoy Sarkar ${ }^{1}$, Ashutosh Tripathy ${ }^{2, *}$ and T N Singh ${ }^{2}$ \\ ${ }^{1}$ Department of Applied Geology, Indian Institute of Technology (Indian School of Mines), Dhanbad \\ 826004 , India. \\ ${ }^{2}$ Department of Earth Sciences, Indian Institute of Technology Bombay, Mumbai 400 076, India. \\ *Corresponding author. e-mail: ashutripathy@iitb.ac.in
}

MS received 26 July 2016; revised 12 April 2017; accepted 5 June 2017; published online 23 November 2017

Several deformation phases in tectonically active Himalayas have rendered the rock masses very complex in terms of structure, lithology and degree of metamorphism. Again, anthropogenic activities such as roads, tunnels and other civil engineering constructions have led to a state of disequilibrium which in many cases, results in failure of rock masses. National Highway-05 around Jhakri area in India is a major connecting route to the China border in the hilly terrains of the state Himachal Pradesh. It cuts through the Himalayan rocks and has a hazardous history of landslides destroying human lives and interrupting communication very frequently. As a contribution towards the mitigation process, a study has been carried out along the highway to analyse kinematic stability and qualitative estimation of rock mass condition through rock mass classification systems. The kinematic analysis shows that the rock slopes are prone to planar and wedge failure. Rock mass rating for most of the locations lies between 7 and 34, representing a poor rock mass quality (Class IV), whereas slope mass rating is more disperse and ranges from 11 to 52 for most of the slopes (Class III, IV and V).

Keywords. Cut slope; kinematic analysis; continuous slope mass rating; geological strength index.

\section{Introduction}

Himachal Pradesh, primarily is a mountainous area with variable climate and uneven rugged topography. It covers parts of Shiwaliks, lesser Himalayas and higher Himalayas with an altitude ranging from 350 to $6975 \mathrm{~m}$ above mean sea level (Srikantia and Bhargava 1998). The mountains in the state are dissected by deep gorges and valleys. Tectonically and morphologically active young and dynamic Himalayas in this region are intersected by many dormant and active thrusts namely Himalayan Frontal Thrust (HFT), the
Main Boundary Thrust (MBT), Main Central Thrust (MCT), the Krol, the Giri, Jutogh and Nahan thrusts. These longitudinal tectonic fractures trend parallel to the Himalayas. Dislocations along these thrusts give rise to earthquake epicentres in the state. The state is assigned under zone IV and $\mathrm{V}$ of earthquake hazard zonation described in India hazard zonation map (Narula et al. 2000). According to National Institute of Disaster Management (NIDM), Govt. of India report, about 250 earthquakes with magnitude 4 and 62 earthquakes having magnitude of 5 and above have impacted the state so far. In addition to earthquakes, 
monsoonal rain causes flood each year in the state which makes the region very prone to landslides. Again, frequent flash floods, cloud bursts and glacial retreat due to global warming weaken the rock mass, making it more vulnerable to failure. Landslide is the most common hazard in the state. Every year one or more major landslides affect the state causing loss of life, property and severe interruption in communication. In addition to rock mass strength and unfavourable orientation of joints and fractures, the intensity and effect of landslide in the area varies with various geophysical factors such as steepness and height of slopes, water ingress in rock joints and fractures, saturation of rock material due to heavy rains, melting snow and ice, seismic vibrations, frost action, change in vegetable cover and toe cutting by rivers and streams. Again, anthropogenic factors as a result of developmental activities such as poorly designed roads, deforestation, unplanned agricultural practice, and encroachment on steep slopes, further aggravate the process. The landslide vulnerability map of Himachal Pradesh is given in figure 1. Many hazardous landslides that have occurred in the past, along the National Highway (NH)-05 in the state have been recorded and the details are shown in table 1.

Apart from above history, another major landslide had occurred in 1993 along NH-05 due to flash flood which damaged $1 \mathrm{~km}$ of road in Jhakri region. The failed mass of the road cut had blocked the Sutlej River. Communication in the highway could be restored only after two months of the event (NIDM, Himachal Pradesh; http://nidm.gov.in/ pdf/dp/himachal.pdf). Also, the road experiences major/minor landslides every year mostly after monsoonal rainfall. District disaster management authority of Shimla has reported the Rampur-Jeori sector, a stretch of $25 \mathrm{~km}$ in $\mathrm{NH}-05$ as landslide vulnerable area.

Keeping an eye on the problems mentioned above, a study was carried out along NH-05 covering a stretch of $12 \mathrm{~km}$ from Jhakri to Jeori in Shimla district, Himachal Pradesh, India. Studied locations are illustrated in Google Earth image (figure 2). The highway is located on the left bank of river Sutlej which makes the situation worse and threatens the stability of the road. Kinematic analysis and rock mass characterisation have been performed to evaluate the rock mass condition. Similar works have been performed recently by Umrao et al. (2015) and Singh et al. (2015). Sarkar et al. (2016) have also assessed the quality of some cut slopes along the same highway.

\section{Geology and geotechnical details}

The Himalayas being a classic example of continent-continent collision, comprises of two distinct tectogens separated by the Main Central Thrust (MCT). These are the lesser Himalayan tectogen and Tethys Himalaya tectogen who bear their own distinct geological history. The studied area from Jhakri to Jeori, a $15 \mathrm{~km}$ stretch in $\mathrm{NH}-$ 05 is present in lesser Himalayan tectogen. The area lies in the Larji-Rampur-Wangtu window zone of Larji tectono-stratigraphic domain (Srikantia and Bhargava 1998). Rocks in this area date back to Paleoproterozoic and Mesoproterozoic and indicate medium to high grade inverted metamorphism (Singh 1979). The rock types in the area are augen migmatite, biotite gneiss, quartz mica schist, garnet bearing quartz mica schist, muscovite biotite schist, and amphibolite, which are truncated by faults and other discontinuities (Singh 1979; Kundu et al. 2016a, b). Regional strike of lithological units is ENE-WSW which shows local variations in the trend (Singh 1979). The geological map of Sarahan Bushair (the investigated area) is given in figure 3 .

A total of 12 locations were selected for the proposed study which covers four major rock types namely, foliated mica schist, strongly foliated mica schist, biotite gneiss, and crenulated mica schist. Rock masses in the area are foliated and blocky in nature, intruded by small quartz veins and commonly intersected by three sets of joints. Joint planes are filled by soft infillings in most rock masses and also remains unfilled in some places. Physical and geomechanical properties in both dry and saturated conditions for the rock materials were determined according to ISRM (1981) specifications. Details of these properties are given in table 2 .

\section{Stability evaluation (qualitative)}

\subsection{Kinematic analysis}

It is an easy practice to use stereographic analysis for the determination of potential failure types and direction in jointed rock mass (Goodman 1976; Hoek and Bray 1981; Matherson 1988). The analysis always indicates geometrically admissible failures which takes slope and joint orientations into consideration. However, friction cone (joint friction angle) has been included in the analysis to 


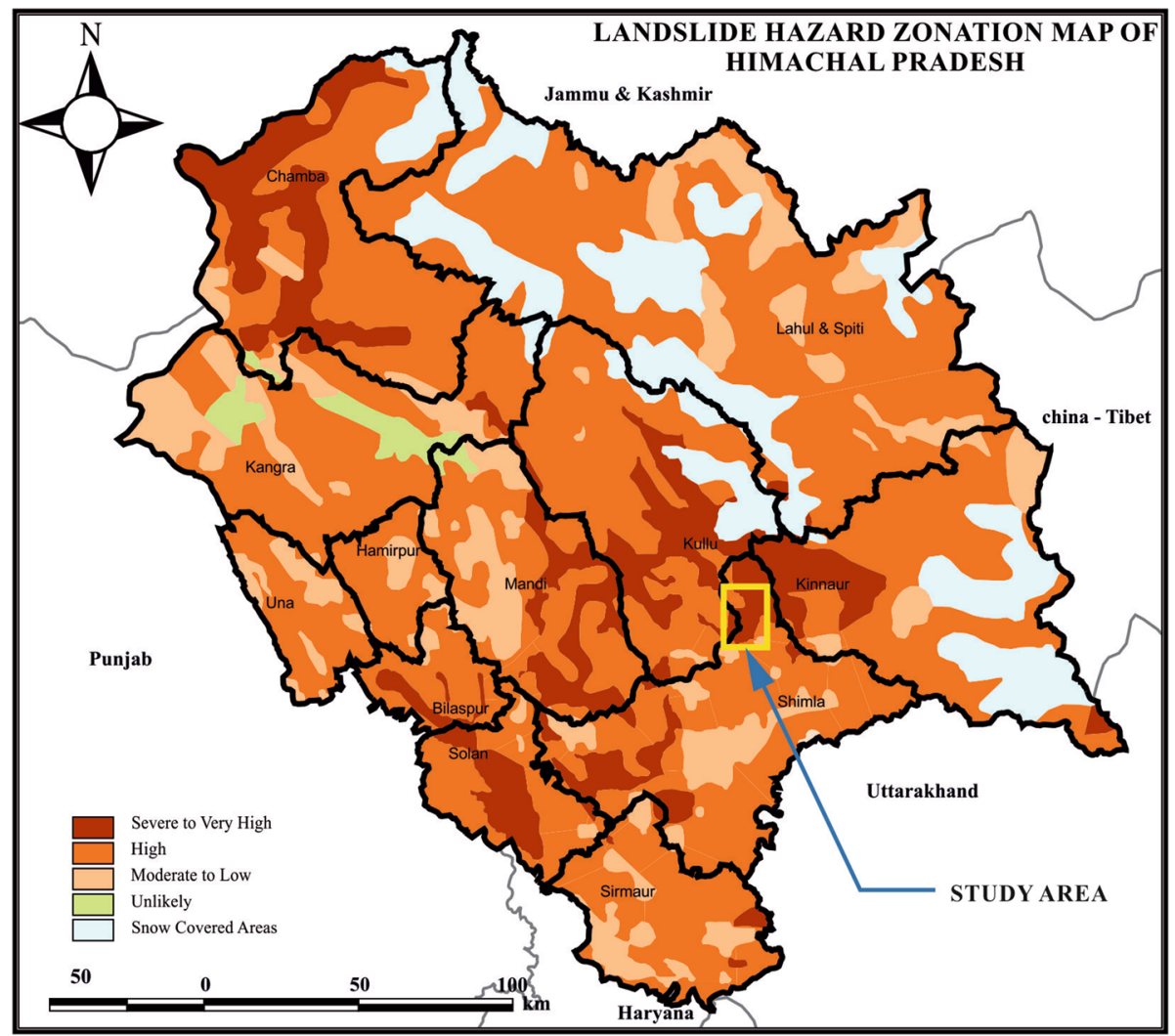

Figure 1. Landslide hazard zonation map of Himachal Pradesh, India (modified from landslide hazard map of SEEDS' 2009 Himachal Pradesh vulnerability atlas).

Table 1. Major landslide history along NH-05 (source: NIDM, Himachal Pradesh; http://nidm.gov.in/pdf/dp/himachal. $p d f)$.

\begin{tabular}{|c|c|c|}
\hline Location/highway & Years & Damage \\
\hline NH-05 & 1988-1995 & $\begin{array}{l}\text { During the flood of } 1988,1993 \text { and } 1995,250,350 \text { and } 475 \mathrm{~m} \text { of road was } \\
\text { washed away }\end{array}$ \\
\hline NH-05, 292-293 km & 1988-1995 & $\begin{array}{l}\text { During the flood of 1988, } 1993 \text { and } 1995,200,500 \text { and } 300 \mathrm{~m} \text { of road was } \\
\text { washed away }\end{array}$ \\
\hline NH-05, 307 km & 1988-1995 & $\begin{array}{l}\text { During the flood of 1988, } 1993 \text { and 1995, 100, } 150 \text { and } 600 \mathrm{~m} \text { of road was } \\
\text { washed away }\end{array}$ \\
\hline
\end{tabular}

satisfy both kinematic and frictional conditions for the failure. Kundu et al. (2016a, b) have modified the technique of kinematic analysis of wedge in a curved slope and analysed a curved slope, where they devised a way to represent varying degree of vulnerability of wedges along a curved slope. A stereonet analysis program DIPS 6.0 (2015) of Rocscience has been used for the analysis in order to find out modes of failure. Eleven slopes have been analysed for which the input parameters are presented in table 3 . It has to be noted that the term 'bedding plane' has been used in this paper under the assumption that joint set having major continuity would represent the same and should not be confused with sedimentary structure. As there are no systematic joints other than some irregular fractures in slope no. 10, it has not been considered for the analysis.

Kinematic analysis for the locations shows that the slopes are highly vulnerable to wedge and planar failure except for slope no. 5 which is kinematically stable. Slope 1 shows potential for wedge failure towards $270^{\circ}$ but with small block sizes (figure 4).

Slope 2 (figure 5) consists of similar joints as of slope 1 and hence represents wedge towards 


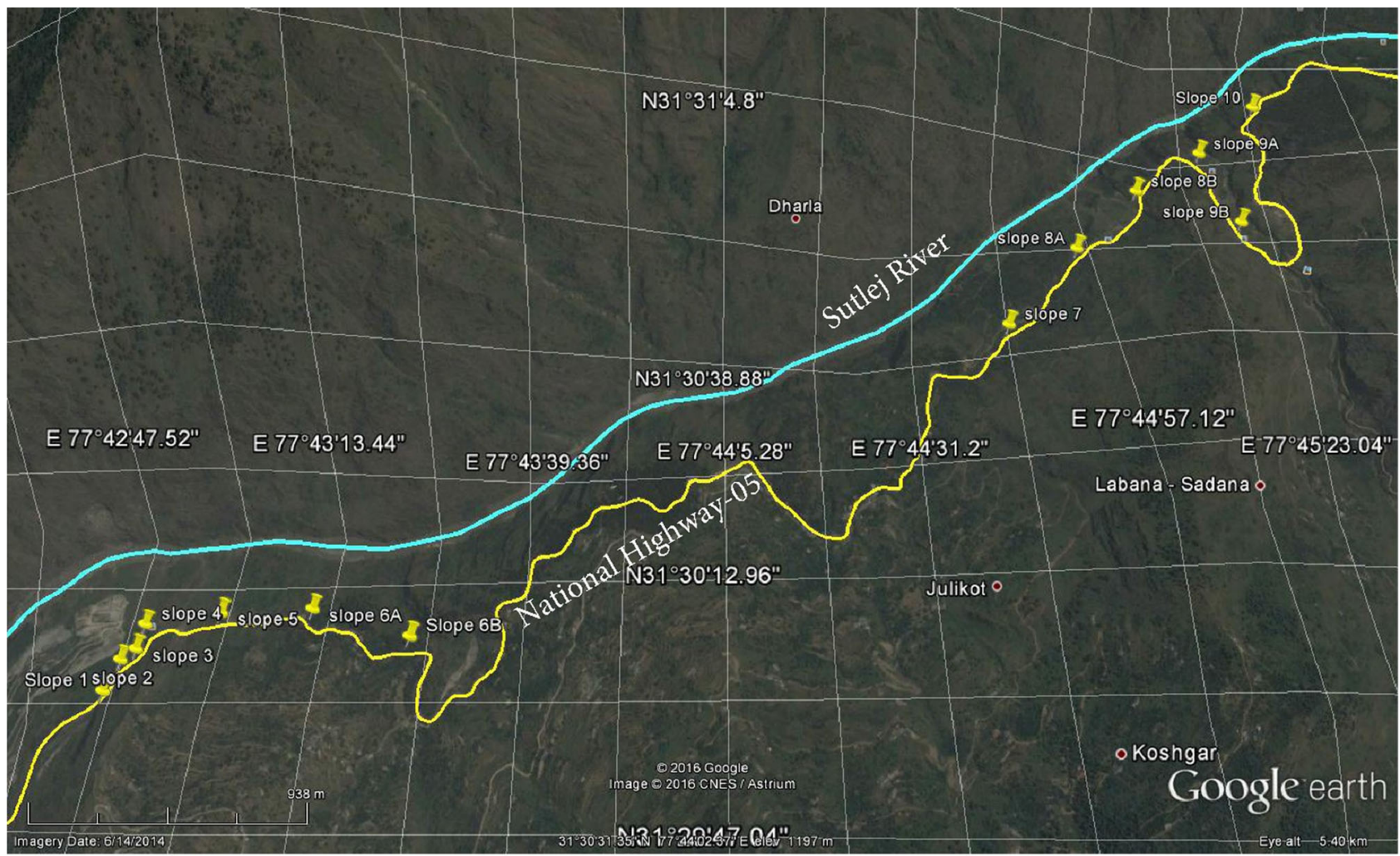

\section{Google Earth Pro}

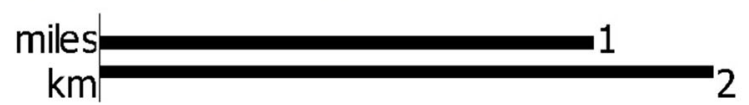

Figure 2. Studied locations plotted in Google Earth image. The yellow line denotes NH-05 and the light blue line represents Sutlej River.

$271^{\circ}$ but with less vulnerability, as the intersection line is not inside the friction cone. Additionally, the slope face orientation, unlike slope 1 facilitates planar failure.

Slope 3 is exposed to wedge failure and trend of the intersection line is towards $301^{\circ}$. As its direction is adjacent to dip direction of the slope, the wedges are more open to failure. Furthermore, the block sizes in this zone measure up to $1.8 \mathrm{~m}^{3}$, making it more hazardous in terms of rock fall (figure 6).

Kinematic analysis has been performed for slope 4 , which represents wedge towards $301^{\circ}$ but failure is not probable due to low plunge angle of the intersection line (intersection point falls outside of failure zones). However, irregular fracture dominates the zone causing failure of rock mass (figure 7).

Slope 5, being more stable in the region, contains only one tight joint set and no possible failure is expected (figure 8). Besides, the location contains very less and insignificant irregular fractures which makes a fair rock mass.
Slope 6A (figure 9) and 6B (figure 10) are weak rock masses intersected by closely spaced joints. Kinematically, the rock masses are exceedingly prone to planar failure. Though analysis for Slope $6 \mathrm{~A}$ shows a wedge failure with intersection line trend $343^{\circ}$, the wedges slip along one plane making single plane wedge failure. Figure 11 represents both planar and wedge failure for slope 7 . Three joint sets form wedges with two failure directions along $293^{\circ}$ and $357^{\circ}$. The wedge with intersection line $357^{\circ}$, fails along the joint plane dipping towards $312^{\circ}$.

Slope 8A comprises rock masses with kinematically unsafe wedges and planes. Intersection lines of probable wedge failures are towards $288^{\circ}$ and $327^{\circ}$. The wedge with intersection line towards $327^{\circ}$ slips along the joint plane dipping towards $216^{\circ}$ (figure 12).

Slope 8B consists of rock mass cliffs with three joint sets, out of which one joint set is responsible for failure. Kinematic analysis shows planar failure towards $270^{\circ}$ (figure 13). 


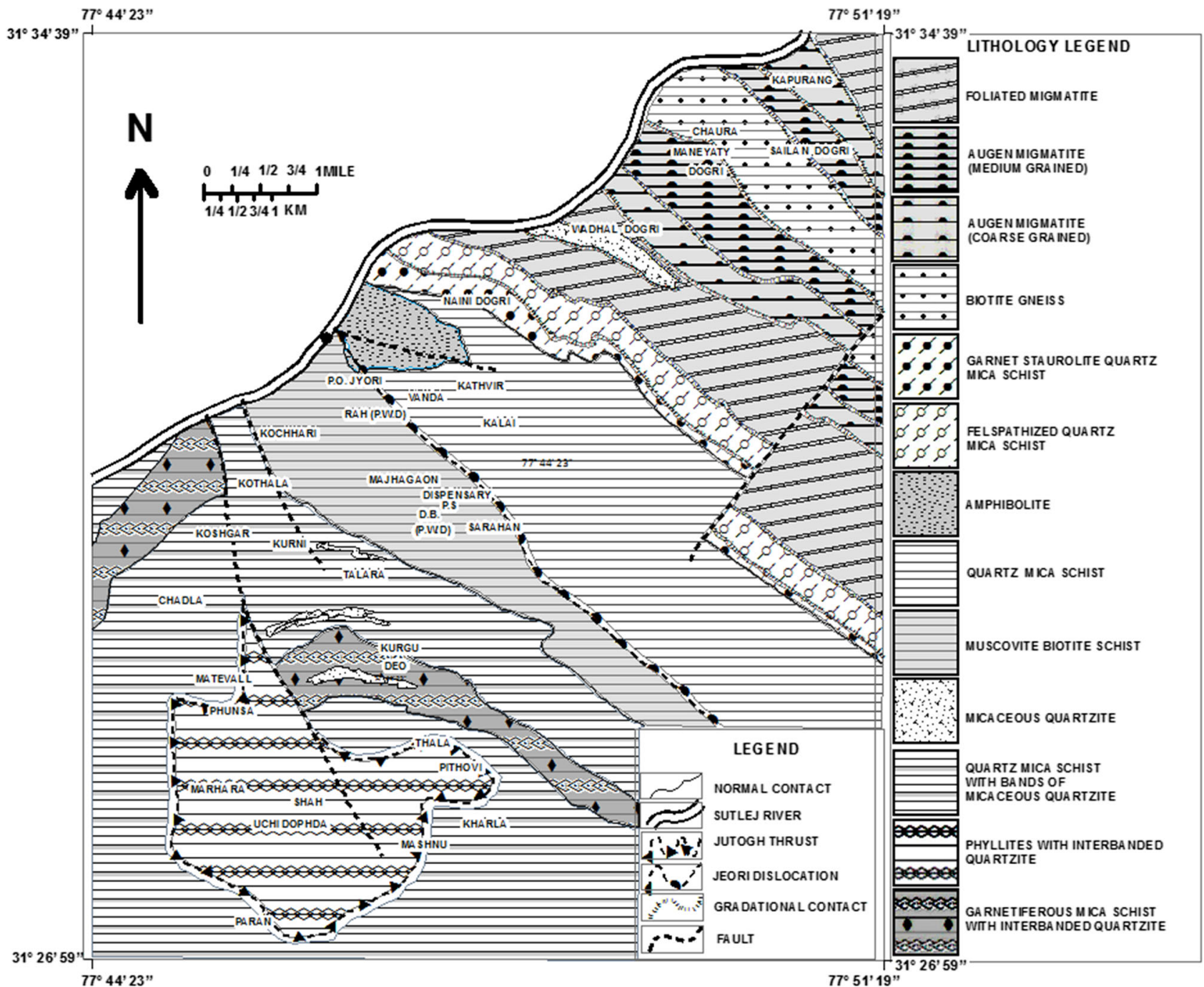

Figure 3. Geological map of Sarahan Bushair area, district Shimla, Himachal Pradesh, India (after Singh 1979).

Table 2. Physical and geotechnical properties of rock materials.

Physical properties

$+$

Dry unit weight

Saturated unit weigh

Slope no. $\quad\left(\mathrm{kN} / \mathrm{m}^{3}\right) \quad\left(\mathrm{kN} / \mathrm{m}^{3}\right)$

27.38

27.31

27.26

27.23

27.19

26.94

26.93

26.71

26.52

26.5

26.36

26.46

26.61

26.79

\section{Porosity}

$(\%)$

2.52

2.47

2.44

2.42

2.39

1.86

1.83

1.59

1.46

1.43

1.39

1.86

.

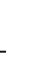

$\longrightarrow$

Geomechanical properties

\begin{tabular}{cc}
\hline Uniaxial & \\
compressive & Tensile strength \\
strength $(\mathrm{MPa})$ & $(\mathrm{MPa})$
\end{tabular}

Water strength (MPa)

Dry Saturated

Dry Saturated

\begin{tabular}{lcccc}
0.91 & 48.2 & 34.3 & 5.1 & 3.6 \\
0.91 & 38.3 & 29.7 & 4.6 & 3.4 \\
0.9 & 36.5 & 27.7 & 4.2 & 3.1 \\
0.89 & 36.3 & 24.3 & 4.0 & 2.6 \\
0.87 & 35.6 & 21.0 & 4.15 & 2.3 \\
0.69 & 42.7 & 26.8 & 4.7 & 2.6 \\
0.68 & 43.4 & 25.3 & 5.2 & 2.7 \\
0.61 & 45.9 & 32.5 & 4.9 & 2.6 \\
0.59 & 54.2 & 41.8 & 6.2 & 3.7 \\
0.56 & 57.1 & 43.0 & 6.3 & 3.9 \\
0.52 & 71.5 & 54.5 & 8 & 5.2 \\
0.68 & 54.6 & 35.9 & 6.2 & 3.6 \\
\hline
\end{tabular}




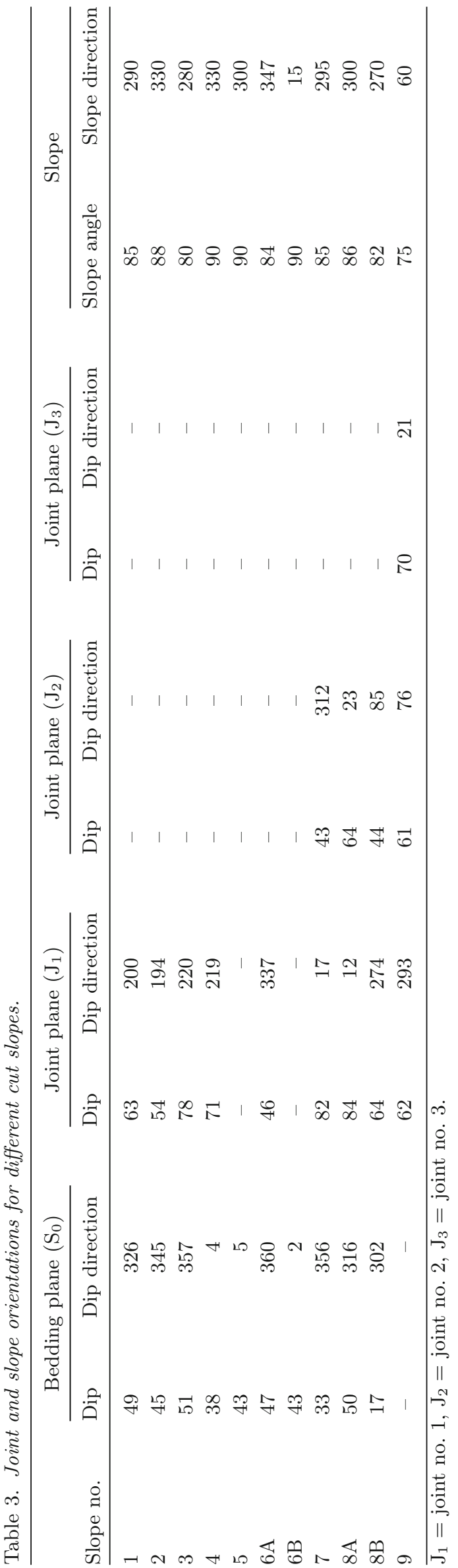

Slope 9 consists of rock mass intersected by three joint sets. The rock blocks are frequently falling due to unstable wedges. The rock mass forms wedges with two potential failure directions towards $4^{\circ}$ and $70^{\circ}$. Wedge with intersection line trend $70^{\circ}$ undergoes single plane wedge failure along the joint plane dipping towards $75^{\circ}$ (figure 14).

\subsection{Rock mass characterisation}

For better communication in rock engineering community, many classification systems have been developed to quantify overall quality of rock mass for different purposes such as tunnelling, mining, foundation and rock slope. Some of the universally accepted and well-established classification systems are Slope Mass Rating (SMR) (Romana 1985; Tomas et al. 2007) for slope mass characterization, Rock Mass Rating (RMR) (Bieniawski 1973, 1976, 1979, 1989) for tunnelling, mining, foundation and slope applications, Rock Mass Quality (Q) (Barton et al. 1974) for tunnelling, Mining Rock Mass Rating (MRMR) (Laubscher 1990), Rock Mass Strength (RMS) (Selby 1980) and Geological Strength Index (GSI) (Hoek et al. 1998; Marinos and Hoek 2000) which is based on visual examination including weak and sheared rock masses. Though RMR was originally developed for tunnelling in moderate to hard rock mass, it was latter modified and adjusted over the years (Weaver 1975; Laubscher 1977, 1984; Romana 1985; Newman and Bieniawski 1986; Venkateswarlu 1986) for the application in mines, foundations, and slopes. Slopes in jointed rock masses are mainly controlled by joint orientations but there is no explicit consideration of the factor in RMR which render the rating system less applicable for slopes (Mahanta et al. 2016). Romana (1985) proposed quantitative definitions for correction factors based on joint orientations and their relationships which lead to SMR system.

This paper covers classification of rock masses along the road cut slopes using conventional Rock Mass Rating (RMR) system proposed by Bieniawski $(1979,1989)$ and modified slope mass rating using continuous functions for correction factors (Tomas et al. 2007) which was originally developed by Romana (1985). Kinematic analysis has been carried out prior to RMR and SMR for the investigated slopes to anticipate potential modes of failure. Then SMR correction factors have been calculated for the identified failure type. Geological strength index also has been calculated for 

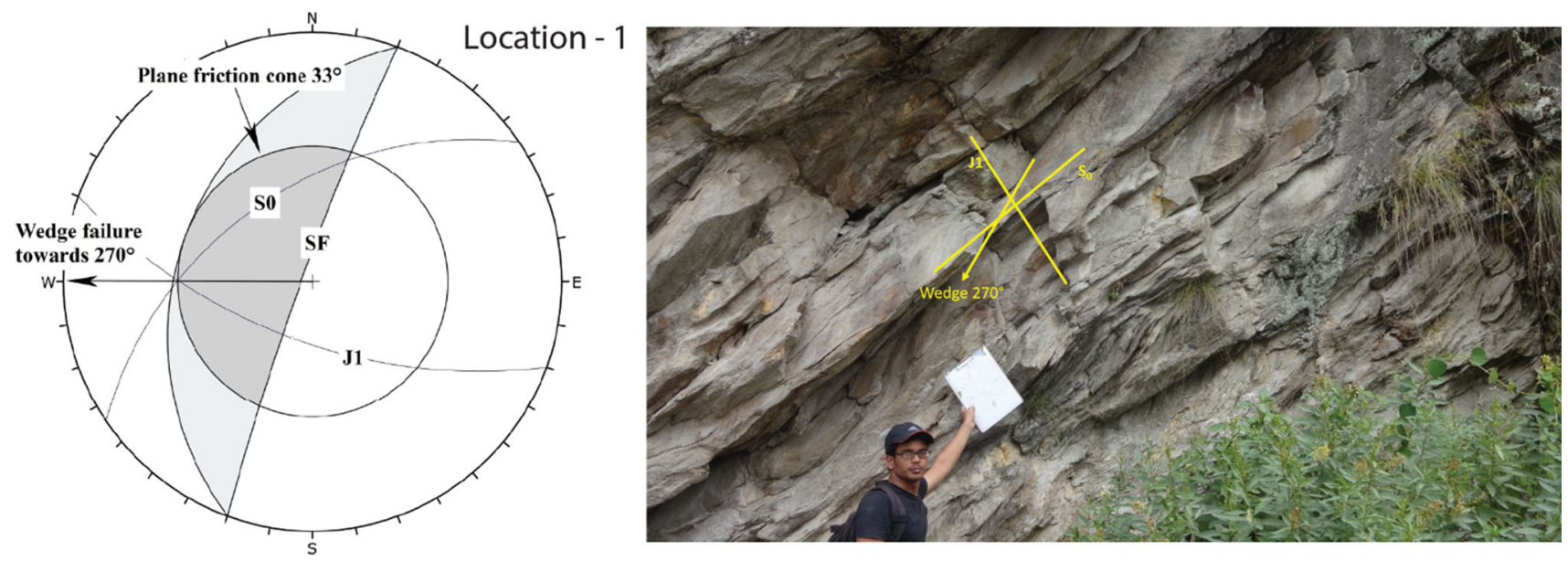

Figure 4. Kinematic analysis for slope no. 1.
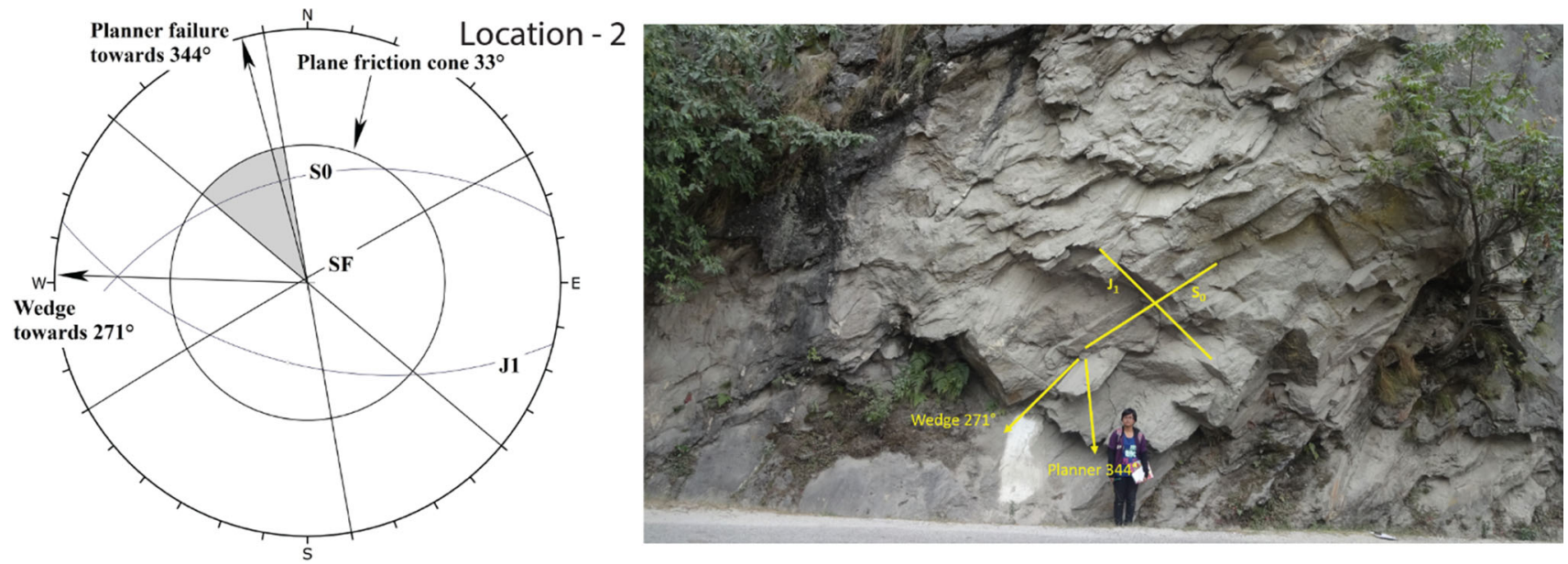

Figure 5. Kinematic analysis for slope no. 2.
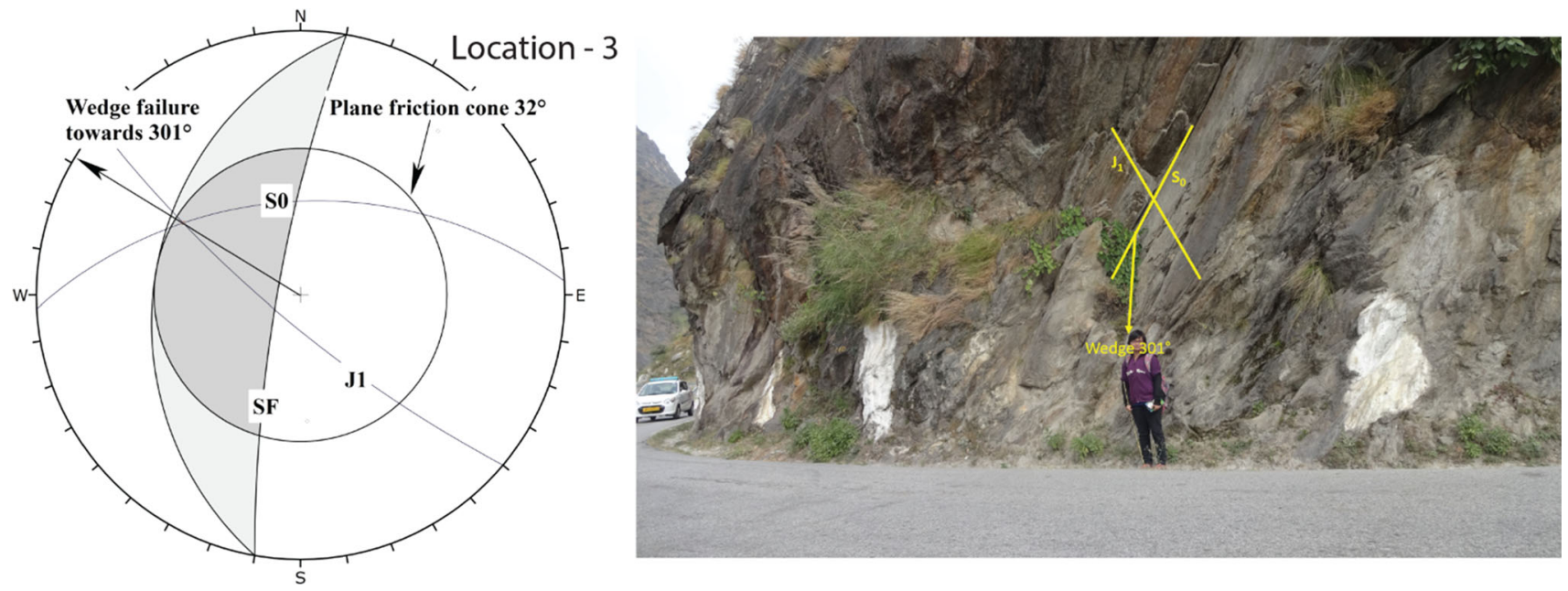

Figure 6. Kinematic analysis for slope no. 3. 

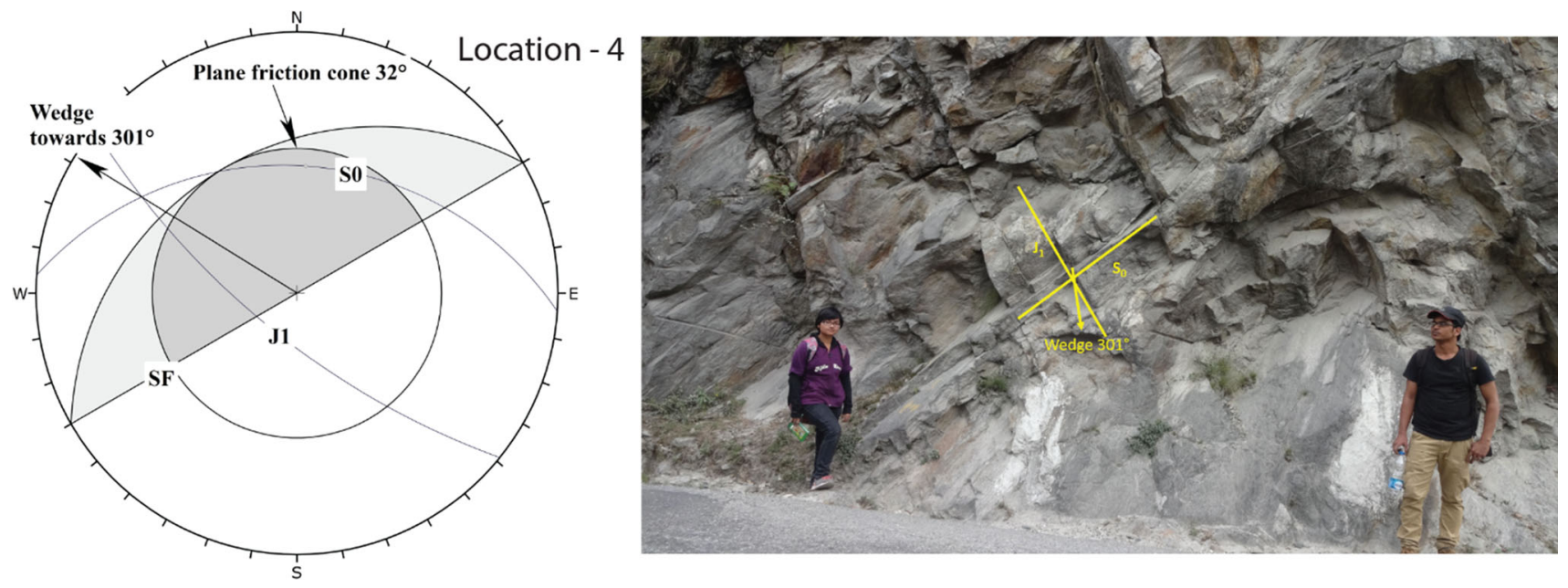

Figure 7. Kinematic analysis for slope no. 4.
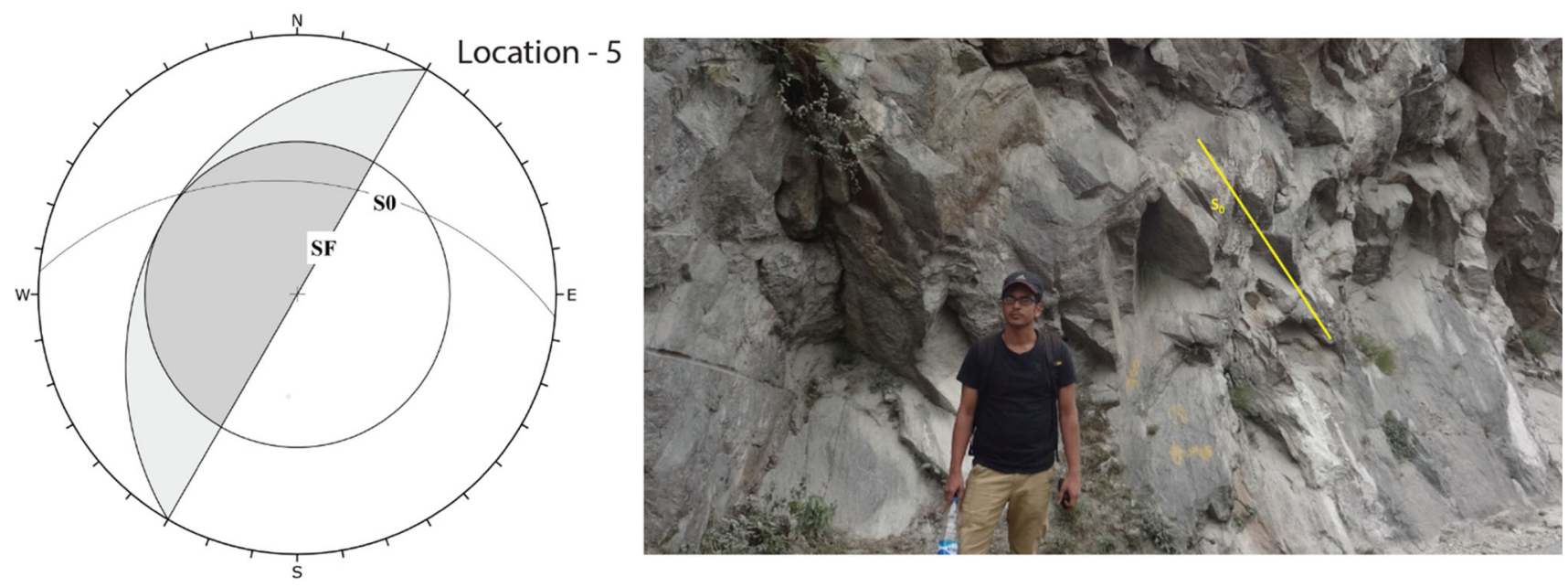

Figure 8. Kinematic analysis for slope no. 5.
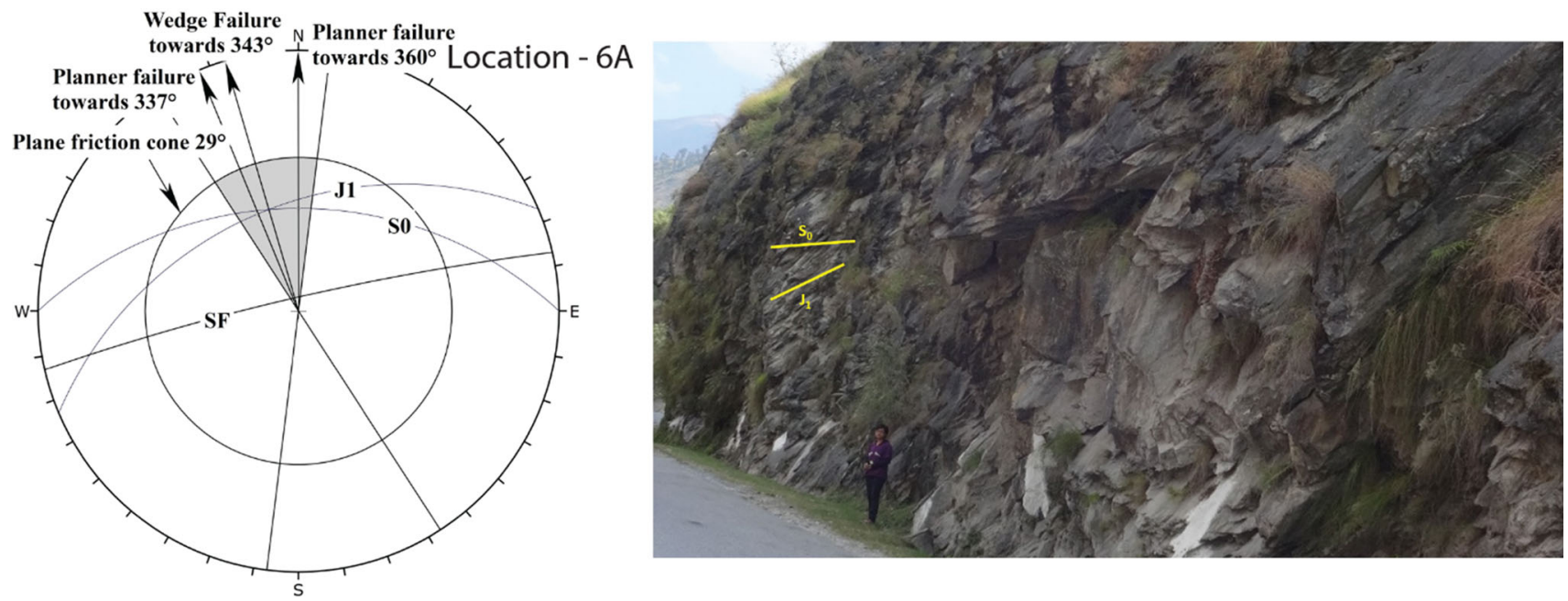

Figure 9. Kinematic analysis for slope no. 6A. 

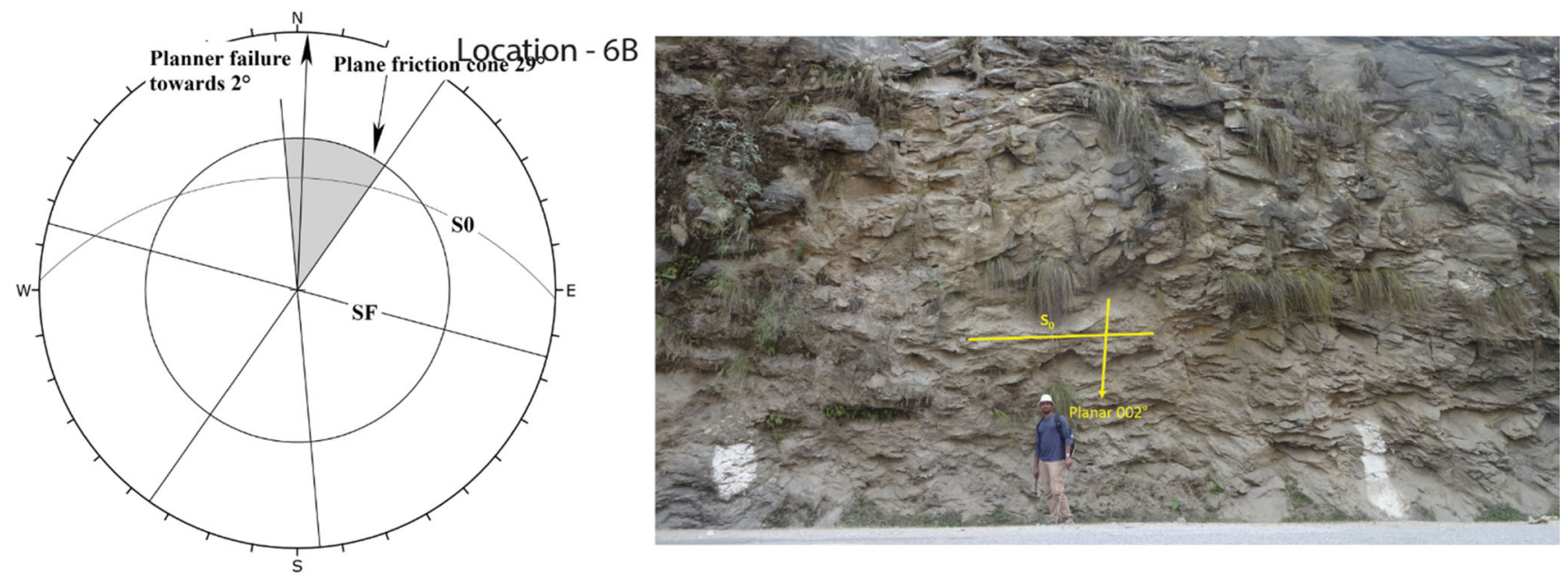

Figure 10. Kinematic analysis for slope no. $6 \mathrm{~B}$.
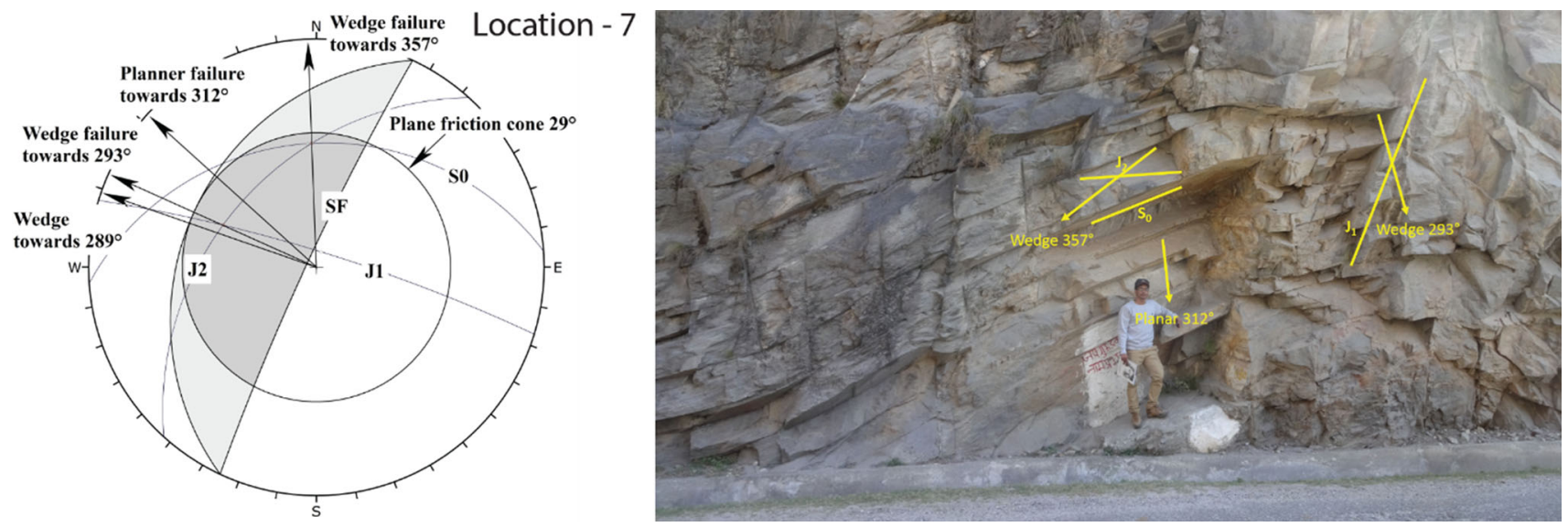

Figure 11. Kinematic analysis for slope no. 7.
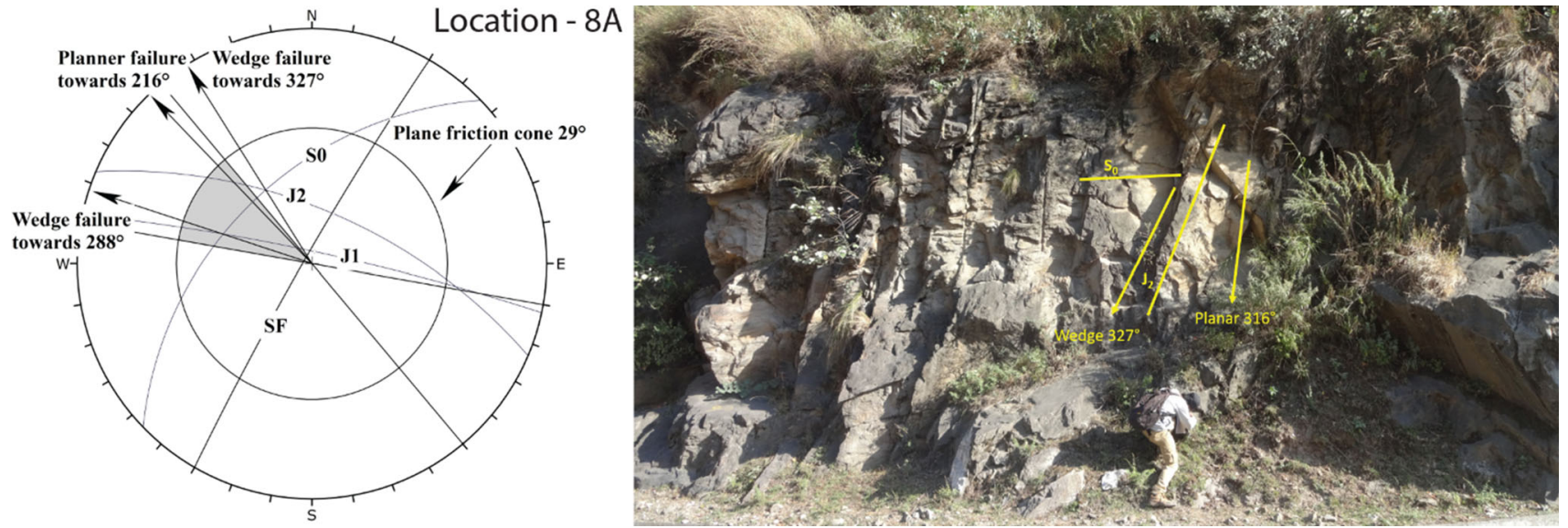

Figure 12. Kinematic analysis for slope no. 8A.

the slopes using quantified method (Sonmez and Ulusay 1999, 2002). Finally, a correlation between basic RMR and GSI is given for the studied area. Twelve slopes were studied out of which RMR, SMR and GSI have been determined directly for 11 slopes. For the slope no. 10, as it does not contain joints except some irregularly oriented fractures, only GSI could be determined from visual observation. Basic RMR has been estimated from the stated correlation (equation 9). 

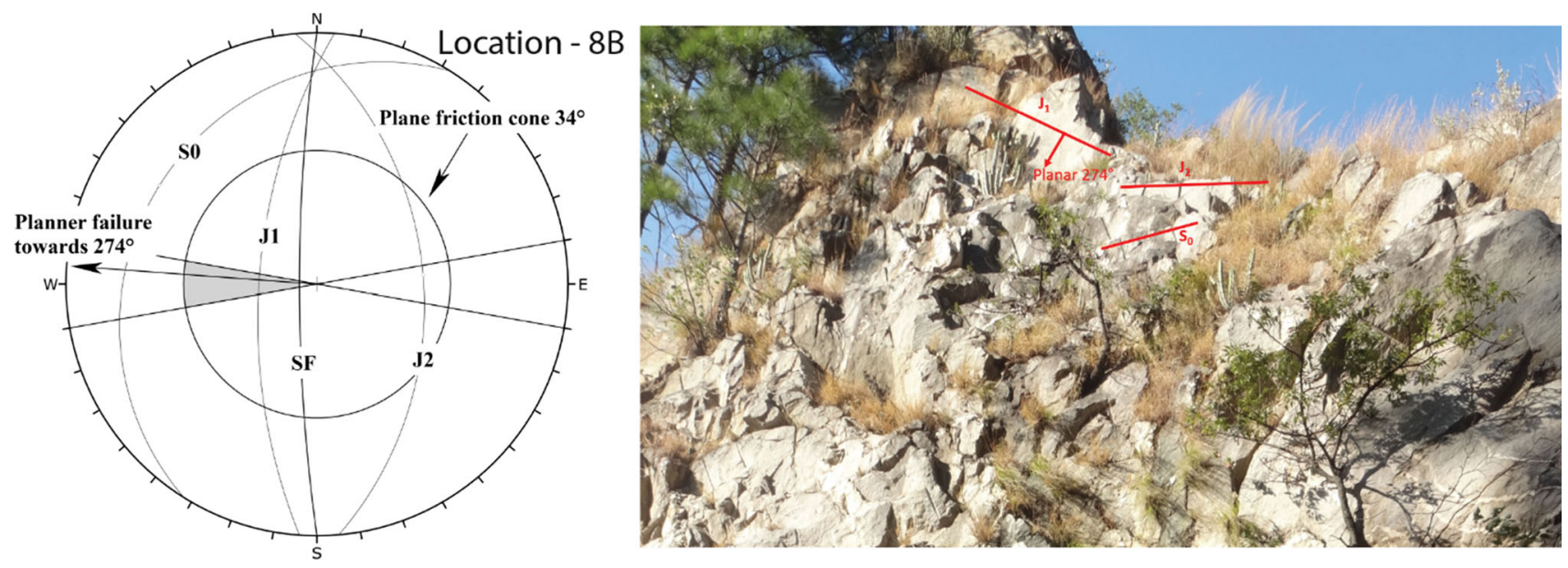

Figure 13. Kinematic analysis for slope no. 8B.
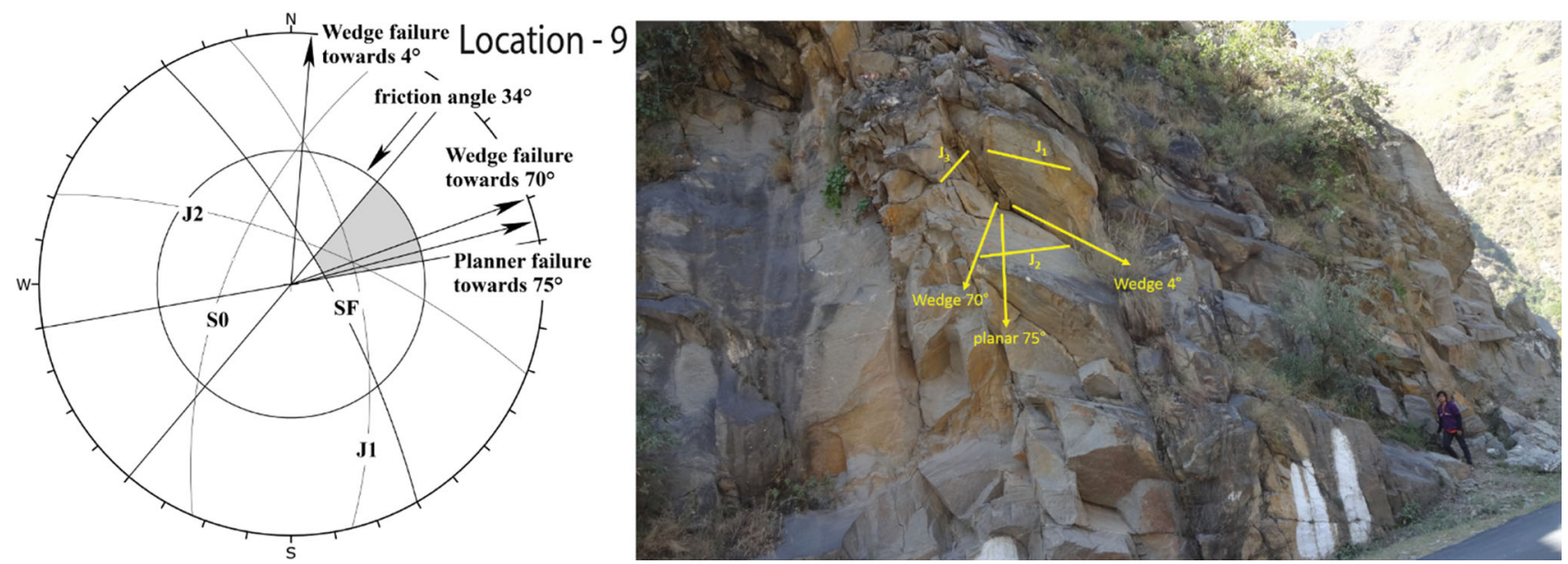

Figure 14. Kinematic analysis for slope no. 9.

\subsubsection{Basic RMR}

The RMR system, which is otherwise known as geomechanics classification, uses six parameters to classify a rock mass which are: (a) uniaxial compressive strength (UCS) of rock material, (b) rock quality designation (RQD), (c) spacing of discontinuities, (d) condition of discontinuities, (e) ground water conditions and (f) orientation of discontinuities. Out of these parameters, quantification for discontinuity orientation is not well defined in the system. Excluding the last one, first five parameters constitute basic RMR which is unadjusted for discontinuity orientations. The fourth parameter, i.e., condition of discontinuities again depends on five subparameters and those are (i) discontinuity persistence, (ii) aperture, (iii) surface roughness, (iv) infilling and (v) weathering.

Slopes were divided into zones based on uniformity in lithology, slope orientation, joint numbers and spacing and each zone was considered separately for the classification. All the required parameters for basic RMR were obtained from field except UCS, which was determined in the laboratory. Individual ratings were given for each parameter and finally added together to find the final rating for the slope mass. The ratings for the parameters are assigned according to Bieniawski (1989). RQD was introduced on the basis of core recovery (Deere 1963), however, as cores are unavailable for the slopes, the relationship given by Palmstrom (1985) has been used to obtain RQD from volumetric joint count $\left(J_{v}\right)$ (Zhang 2016). $J_{v}$ is the total number of joints encountered in a cubic metre volume of rock mass. The relationship is given by

$$
\mathrm{RQD}=115-3.3 J_{v} .
$$

Basic RMR (RMR basic $\left._{\text {f }}\right)$ for each slope has been calculated to determine RMR and SMR and is given 
in table 4. Slope 5 has the highest value of 63 and slope $6 \mathrm{~A}$ being the lowest, has got a value 40.5. The RMR for the cut slopes has been determined by adding the adjustment factors for joint orientation given by Bieniawski (1989). There are some slopes (slopes $6 \mathrm{~A}$ and $6 \mathrm{~B}$ ) which show negative RMR. This negative value can be attributed to high adjustment factor for joint orientation and should be considered in the very poor quality category, representing the rock mass in Class $\mathrm{V}$ of Bieniawski (1989) interpretation. According to his interpretation, all other slopes belong to Class III and IV, representing poor to fair rock mass quality.

\subsubsection{Continuous SMR}

Romana (1985) proposed SMR system by adding four correction factors to the basic RMR. Out of four, three correction factors depend on the relationship between discontinuities and the fourth one depends upon slope excavation method. Initially SMR was proposed for planar and topple failure and the ratings for wedge failure was added to the system by Anbalagan et al. (1992). The expression for continuous SMR is same as SMR and is as follows (Singh and Goel 1999)

$$
\mathrm{SMR}=\mathrm{RMR}_{\text {basic }}+\mathrm{F}_{1} \times \mathrm{F}_{2} \times \mathrm{F}_{3}+\mathrm{F}_{4}
$$

where F1 depends on difference between dip direction of joint $(\alpha \mathrm{j})$ and slope $(\alpha \mathrm{s})$. In case of wedge failure, it depends on difference between $\alpha$ s and trend of line of intersection $\alpha$ i.

$\mathrm{F} 2$ depends on dip of joint $(\beta \mathrm{j})$ in case of planar failure and plunge of line of intersection $(\beta \mathrm{i})$ in case of wedge failure. For toppling failure, F2 remains 1 everywhere.

F3 depends on difference between $\beta \mathrm{j}$ and dip of slope $(\beta \mathrm{s})$ for planar failure and difference between $\beta \mathrm{i}$ and $\beta \mathrm{s}$ for wedge failure. For topple failure, it depends on $\beta \mathrm{j}+\beta \mathrm{s}$.

F4 is the adjustment for method of excavation.

The ratings suggested by Romana (1985) for F1, F2, F3, and F4 are discrete and relies more on judgement of the investigator. So it needs an experienced person to allocate rating for the factors. Tomas et al. (2007) suggested continuous functions for F1, F2 and F3 which best fits the discrete values.

He has given the following equations for the continuous functions:

$$
\mathrm{F}_{1}=\frac{16}{25}-\frac{3}{500} \tan ^{-1}\left(\frac{1}{10}(|A|-17)\right),
$$

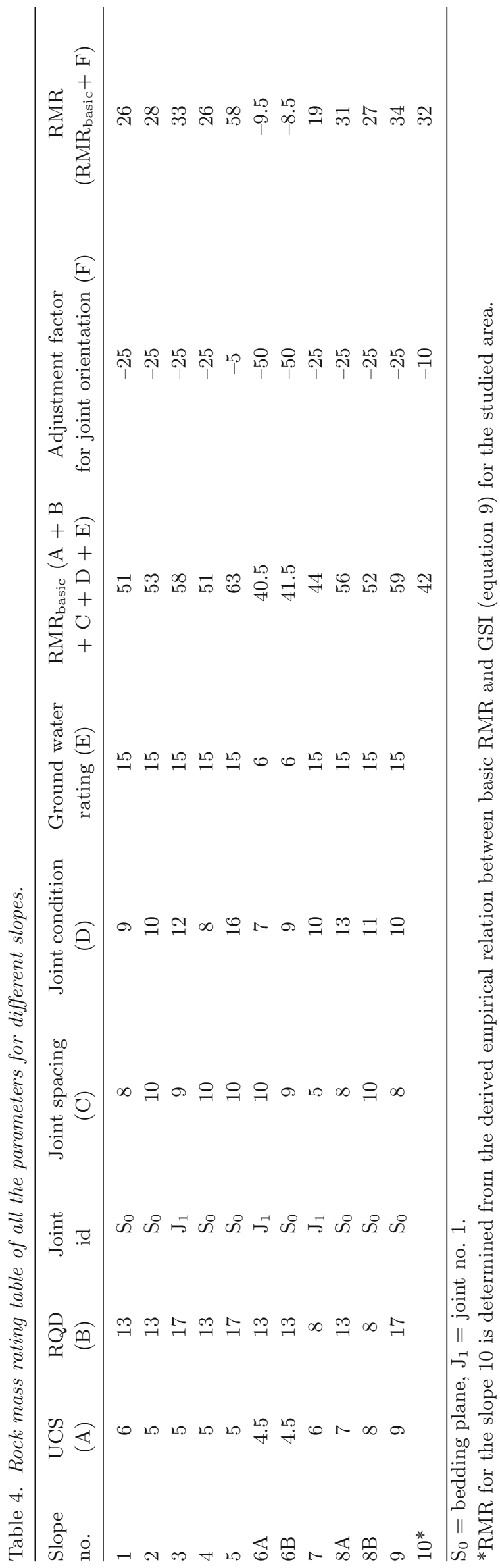




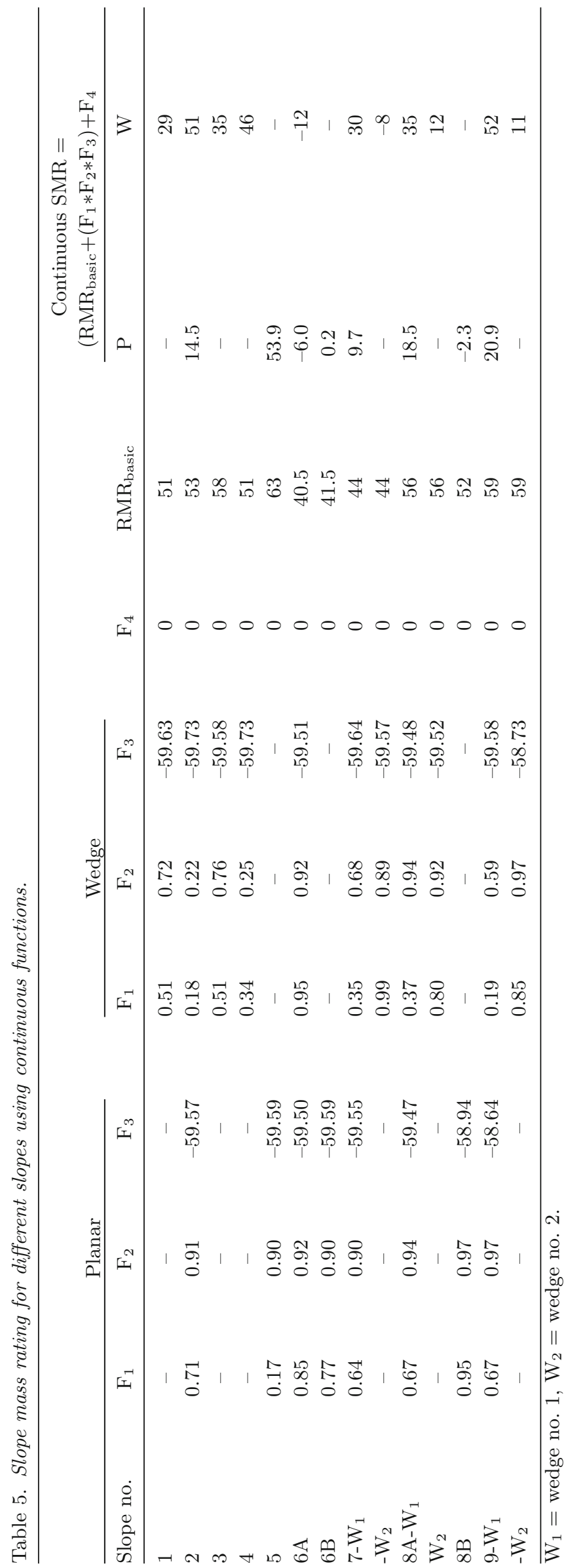

$$
\mathrm{F}_{2}=\frac{9}{16}+\frac{1}{195} \tan ^{-1}\left(\frac{17}{100} B-5\right) \text {. }
$$

For planar and wedge failure,

$$
\mathrm{F}_{3}=-30+\frac{1}{3} \tan ^{-1} C .
$$

And for topple failure,

$$
\mathrm{F}_{3}=-13-\frac{1}{7} \tan ^{-1}(C-120)
$$

where $A=$ parallelism between slope strike and joint strike for planar and toppling failures and difference between slope strike and plunge direction of angle of intersection for wedge failure. $B=$ dip of joint in planar failure and plunge of angle of intersection in wedge failure.

$C=$ difference between angle of slope and dip of joint for planar failure, difference between angle of slope and plunge of line of intersection for wedge failure and addition of slope angle and dip of joint, in case of toppling failure.

The adjustment factors for SMR have been determined from continuous functions from equations (3, 4 and 5). All the slopes excluding slope 10 (due to unavailability of joints or systematic fractures) have been classified according to SMR system. The ratings for planar and wedge failures are given in table 5 . The rock masses are very bad to bad in quality for most of the slopes and normal for slopes 4 and 5 . Negative values are obtained for slope $6 \mathrm{~A}$ and $8 \mathrm{~B}$ for planar failure and $6 \mathrm{~A}$ and 7 for wedge failure. These slopes with negative values can be considered in very bad rock mass and represent Class V of Romana (1985) interpretation. Slopes 4 and 5 represent the rock mass in Class III. Slopes 1 and 3 come under the Class IV, while slopes 2, 6B, 8A and 9 are in Class V. Romana (1985) has given a stability interpretation for slopes on the basis of SMR. Accordingly, slopes 2, 6A, $6 \mathrm{~B}, 7,8 \mathrm{~A}, 8 \mathrm{~B}$ and 9 are in very critical condition (completely unstable), slopes 1 and 3 are unstable, while slopes 4 and 5 are partially stable. From the field observations, it is envisaged that for slope nos $2,4,8 \mathrm{~B}$ and 9 , the stability is underestimated by SMR. This is due to exclusion of shear strength of joints in the rating system. However, if we count for the shear strength of the joints, it may provide a better approximation to the natural condition. For this type of conflict in the rating systems, solutions through numerical simulation is suggested by many researchers. 


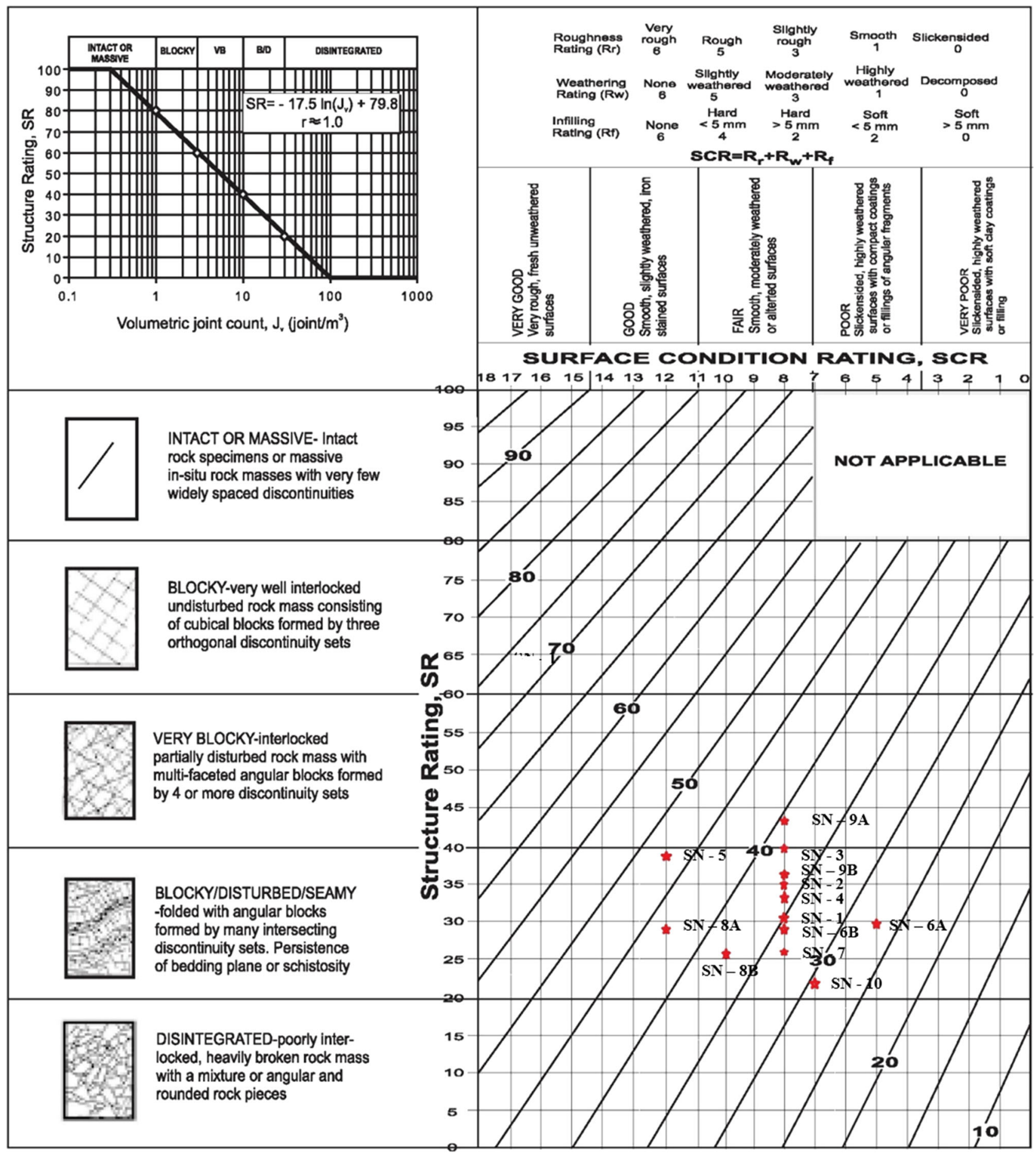

$\mathrm{SN}=$ Slope number

Figure 15. Plotted values in SR vs. SCR graph from Sonmez and Ulusay (2002) to obtain GSI.

\subsubsection{Geological strength index}

Geological strength index (GSI) is a convenient rock mass classification system which can be estimated in the field from visual observation of blockiness and discontinuity surface conditions of the rock mass (Hoek et al. 1998). Though it does not consider discontinuity orientation, it is very helpful in determining overall rock mass health. The GSI for 11 slopes have been calculated according to modified quantitative GSI system proposed by Sonmez and Ulusay (1999, 2002), while slope no. 10 is estimated from visual observations (Hoek et al. 1998; Marinos and Hoek 2000). There are two 
Table 6. Quantified GSI for studied slopes.

\begin{tabular}{lccccccc}
\hline $\begin{array}{l}\text { Slope } \\
\text { no. }\end{array}$ & $\mathrm{J}_{\mathrm{v}}$ & $\mathrm{SR}$ & $\mathrm{R}_{\mathrm{r}}$ & $\mathrm{R}_{\mathrm{f}}$ & $\mathrm{R}_{\mathrm{w}}$ & $\mathrm{SCR}$ & GSI \\
\hline 1 & 17 & 30.2 & 3 & 2 & 3 & 8 & 35 \\
2 & 13 & 34.9 & 3 & 0 & 5 & 8 & 36 \\
3 & 10 & 39.5 & 3 & 2 & 3 & 8 & 38 \\
4 & 14 & 33.6 & 3 & 0 & 5 & 8 & 36 \\
5 & 11 & 37.8 & 5 & 2 & 5 & 12 & 47 \\
$6 \mathrm{~A}$ & 18 & 29.2 & 2 & 0 & 3 & 5 & 27 \\
$6 \mathrm{~B}$ & 18 & 29.2 & 3 & 0 & 5 & 8 & 34 \\
7 & 21 & 26.5 & 3 & 0 & 5 & 8 & 33 \\
$8 \mathrm{~A}$ & 19 & 28.3 & 5 & 2 & 5 & 12 & 43 \\
$8 \mathrm{~B}$ & 21 & 26.5 & 5 & 0 & 5 & 10 & 37 \\
9 & 8 & 43.4 & 3 & 0 & 5 & 8 & 39 \\
10 & - & - & - & - & - & - & 29 \\
\hline
\end{tabular}

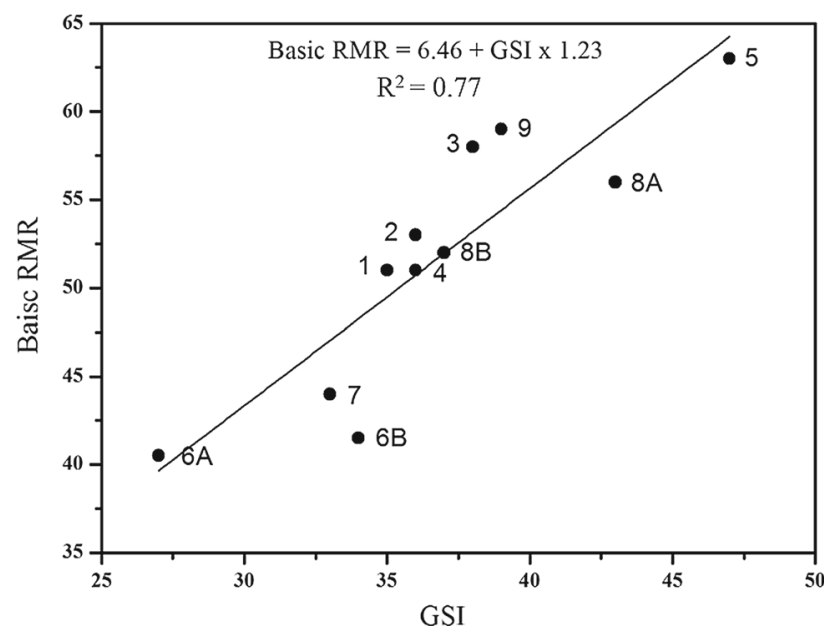

Figure 16. Linear correlation of $\mathrm{RMR}_{\text {basic }}$ and GSI for 11 slopes of the studied area.

factors considered for the index, one is structure rating (SR) and another is surface condition rating (SCR). These two factors are represented by the following equations (Sonmez and Ulusay 2002).

$$
\begin{aligned}
\mathrm{SR} & =17 \ln J_{v}+79.8 \\
\mathrm{SCR} & =R_{r}+R_{w}+R_{f}
\end{aligned}
$$

where $J_{v}=$ volumetric joint count, $R_{r}=$ roughness rating, $R_{w}=$ weathering rating, and $R_{f}=$ Infilling rating.

The value of SR and SCR are plotted in the graph (figure 15) to obtain GSI. The GSI value for slope no. 10 is estimated from visual observation. Obtained quantified GSI are given in table 6 .

A correlation has been derived from linear fitting of $\mathrm{RMR}_{\text {basic }} v s$. GSI for 11 slopes for the studied area (figure 16). The equation derived from empirical relation is

$$
\text { Basic } \mathrm{RMR}=6.46+\text { GSI } \times 1.23 .
$$

This empirical equation may be well applicable to rock masses of similar kind of lithology and geological structures which are highly disturbed.

\section{Conclusions}

The kinematic analysis and geomechanical classifications of the rock mass are very important tools for the assessment of vulnerable slopes. Twelve cut slopes have been taken along NH-05 in Jhakri area and the SMR values indicate that the rock masses range from very bad to bad in quality for most of the slopes and normal for slope 5. The RMR represents poor to very poor rock mass quality except for location 5 which is fair in quality. Moreover, the kinematic results match with the field observations. The results obtained through continuous SMR can be useful in designing support systems and to strengthen the existing vulnerable slopes for safe transportation in the study area. It is further recommended to conduct numerical analysis for those slopes where SMR seems to underestimate the stability due to high joint shear strength.

\section{Acknowledgements}

The authors express their sincere acknowledgement to the Department of Earth Sciences, IIT Bombay, for providing facilities to conduct experimental works. The authors are also thankful to IIT (ISM) Dhanbad for providing financial support for Dips 6.0 from Faculty Research Scheme (Project No: FRS (46)/2013-2014/AGL).

\section{References}

Anbalagan R, Sharma S and Raghuvanshi T K 1992 Rock mass stability evaluation using modified SMR approach; In: Proceedings 6th Natural Symposium on Rock Mechanics, Bangalore, India, pp. 258-268.

Barton N, Lien R and Lunde J 1974 Engineering classification of rock masses for the design of tunnel support; Rock Mechanics 6(4) 189-236.

Bieniawski Z T 1973 Engineering classification of jointed rock masses; Trans. S. Afr. Inst. Civ. Eng. 15 335-344. 
Bieniawski Z T 1976 Rock mass classification in rock engineering; In: Proceedings of the symposium on explore for rock engineering, Johannesburg, pp. 97-106.

Bieniawski Z T 1979 The geomechanical classification in rock engineering applications; In: Proceedings of 4 th International Congress on Rock Mechanics, International Society for Rock Mechanics, Salzburg, 2 41-48.

Bieniawski Z T 1989 Engineering rock mass classification; Chichester, Wiley, London.

Deere D U 1963 Technical description of rock cores for engineering purposes; Rock Mech. Eng. Geol. 1 16-22.

Goodman R E 1976 Methods of geological engineering in discontinuous rocks; West Publishing, San Francisco.

Hoek E and Bray J W 1981 Rock slope engineering; Institution of Mining and Metallurgy, London.

Hoek E, Marinos P and Benissi M 1998 Applicability of the Geological Strength Index (GSI) classification for very weak and sheared rock masses: The case of the Athens Schist Formation; Bull. Eng. Geol. Env. 57(2) 151-160.

International Society of Rock Mechanics (ISRM) 1981 Rock characterization testing and monitoring: ISRM suggested methods; Pergamon Press, London.

Kundu J, Sarkar K and Singh A K 2016 Integrating structural and numerical solutions for road cut slope stability analysis - A case study, India; In: Rock Dynamics: From Research to Engineering, Proceedings of the 2nd International Conference on Rock Dynamics and Applications, pp. 457-462.

Kundu J, Mahanta B, Tripathy A, Sarkar K and Singh T N 2016 Stability evaluation of jointed rock slope with curved face; In: INDOROCK 2016, pp. 971-978.

Laubscher D H 1977 Geomechanics classification of jointed rock masses-mining applications; Trans. Inst. Min. Metall. Sect. A - Mining Industry 86 A1-A8.

Laubscher D H 1984 Design aspects and effectiveness of support in different mining conditions; Trans. Inst. Min. Metall. Sect. A - Mining Industry 93 A70-A81.

Laubscher D H 1990 A geomechanics classification system for the rating of rock mass in mine design; J. S. Atr. Inst. Min. Metall. 90 257-273.

Mahanta B, Singh H O, Singh P K, Kainthola A and Singh T N 2016 Stability analysis of potential failure zones along NH-305, India; Natural Hazards, https://doi.org/10.1007/ s11069-016-2396-8.

Marinos P and Hoek E 2000 GSI - A geologically friendly tool for rock mass strength estimation; In: Proceedings of GeoEng2000 Conference, Melbourne, pp. 1422-1442.

Matherson G D 1988 The collection and use of field discontinuity data in rock slope design; Quart. J. Eng. Geol. 22 19-30.

Narula P L, Shanker R and Chopra C 2000 Rupture mechanism of Chamoli earthquake of 29th March 1999 and its implications for seismotectonics of Garwal Himalaya; $J$. Geol. Soc. India 55(5) 493-503.
Newman D A and Bieniawski Z T 1986 Modified version of the geomechanics classification for entry design in underground coal mines; Trans. Soc. Min. Eng. AIME 280 2134-2138.

Palmstrom A 1985 Application of the volumetric joint count as a measure of rock mass jointing; In: Proceedings of the International Symposium on Fundamentals of Rock Joints, Bjorkliden, Sweden, pp. 103-110.

Romana M 1985 New adjustment ratings for application of Bieniawski classification to slopes; In: Proceedings of International Symposium on Role of Rock Mech, ISRM, Zacatecas, Mexico, pp. 49-53.

Sarkar K, Singh A K, Niyogi A, Behera P K, Verma A K and Singh T N 2016 The assessment of slope stability along NH-05 in Rampur-Jhakri Area, Himachal Pradesh; J. Geol. Soc. India 88 387-393, https://doi.org/10.1007/ s12594-016-0500-z.

Selby M J 1980 A rock mass strength classification for geomorphic purposes: With tests from Antarctica and New Zealand; Z. Geomorpho. 24 31-51.

Singh B and Goel R K 1999 Rock mass classification. A practical approach in civil engineering; Elsevier.

Singh K P 1979 Deformation history of the rocks around Sarahan Bushair, Himachal Pradesh; In: Structural geology of the Himalaya (ed.) Saklani P S, pp. 163-182.

Singh P K, Kainthola A and Singh T N 2015 Rock mass assessment along the right bank of river Sutlej, Luhri, Himachal Pradesh, India; Geomatics. Nat. Hazards Risk 6 212-223, https://doi.org/10.1080/19475705.2013.834486.

Sonmez H and Ulusay R 1999 Modifications to the geological strength index (GSI) and their applicability to stability of slopes; Int. J. Rock Mech. Mining Sci. 36 743-760.

Sonmez H and Ulusay R 2002 A discussion on the HoekBrown failure criterion and suggested modifications to the criterion verified by slope stability case studies; Yerbilimleri (Earth Sci.) 26 77-99.

Srikantia S V and Bhargava O N 1998 Geology of Himachal Pradesh; Geol. Soc. India.

Tomas R, Delgado J and Seron J B 2007 Modification of slope mass rating (SMR) by continuous functions; Int. J. Rock Mech. Mining Sci. 44 1062-1069.

Umrao R K, Singh R and Singh T N 2015 Stability evaluation of hill cut slopes along National Highway-13 near Hospet, Karnataka, India; Georisk Assess. Manag. Risk Eng. Syst. Geohazards 1-13, https://doi.org/10.1080/ 17499518.2015.1053494.

Venkateswarlu V 1986 Geomechanics classification of coal measure rocks vis-a-vis roof supports; Ph.D. thesis, Indian School of Mines, Dhanbad.

Weaver J 1975 Geological factors significant in the assessment of rippability; Civ. Eng. S. Afr. 17 313-316.

Zhang L 2016 Determination and applications of rock quality designation (RQD); J. Rock Mech. Geotech. Eng., https:// doi.org/10.1016/j.jrmge.2015.11.008. 